\title{
Iconografía del desastre. El incendio de la Iglesia de la Compañía, Santiago (1863)
}

\author{
Disaster Iconography. \\ The Fire Of The Church Of The Company, Santiago (1863) \\ Antonio Marrero Alberto \\ CO-INV proyecto ANID Regular FONDECYT no 1201032 \\ antoniomarreroalberto@gmail.com
}

¡que el sol no seca tan pronto las huellas de la reciente lluvia, como el tiempo hace olvidar los mas grandes dolores, una vez pasados!

(Riquelme, 1893: 7)

\section{Resumen:}

A lo largo de los siglos XIX y XX, Chile hace grandes esfuerzos por gestar una identidad nacional que ampare y cobije a todos sus habitantes bajo un signo común. Las manifestaciones artísticas serán empleadas como medio tangible para conseguir semejante fin, caracterizándose por la aceptación de las ideas ilustradas y el cuestionamiento de su pasado hispano. Si bien esta aseveración responde a las intenciones manifiestas de la elite intelectual santiaguina, las clases sociales, alejadas de la anterior, siguen leyendo en clave colonial. En este articulo pretendemos abordar la necesidad de generar nuevas tipologías iconográficas, con base en hitos históricos nacionales, entre los cuales destaca el incendio de la iglesia de la Compañía en 1863. La iglesia jesuítica, paradigmática en su decoración y máximo exponente arquitectónico de los tiempos de la Capitanía, arde hasta sus cimientos en un acontecimiento de calado mundial y que algunos quisieron ver como el fin absoluto de un pasado negado durante la República.

Palabras clave: iconografía, iglesia de la Compañía, incendio, pintura, Santiago.
Abstract:
Throughout the 19th and 20th centuries, Chile made great efforts to create a national identity that pro- tects and shelters all its inhabitants under a common sign. The artistic manifestations will be used as a tangible means to achieve such an end, characterized by the acceptance of the illustrated ideas and the questioning of its Hispanic past. Although this assertion responds to the manifest intentions of the 
Santiago intellectual elite, the social classes, far from the former, continue to read in a colonial key. In this article we intend to address the need to generate new iconographic typologies, based on national historical landmarks, among which the burning of the Church of the Company in 1863 stands out. The Jesuit church, paradigmatic in its decoration and the greatest architectural exponent of the times. of the Captaincy, burns to its foundations in an event of global significance and that some wanted to see as the absolute end of a past denied during the Republic.

Key words: iconography, church of the Company, fire, picture, Santiago.

Recibido: 30 de abril 2021 • Aceptado: 23 de julio 2021

\section{Introducción}

Los estudios de iconografía abordan los códigos que permiten la identificación del tema representado, así como el análisis del contexto histórico a partir de la aplicación del método iconológico (Panofsky, 2004: 45-71). La identificación de elementos paradigmáticos asociados a un pueblo o nación son claves para la conformación de una identidad propia y Chile no será ajena a esta realidad, gestando tipologías que desembocarán en un sentimiento de comunidad en todos los chilenos.

Al mismo tiempo, la independencia de Chile del imperio español en la segunda década del siglo XIX ha querido ser vista como la ruptura entre el arte colonial y las nuevas prácticas artísticas enmarcadas por la República. Esta se mueve al son de aires ilustrados provenientes de países culturalmente pujantes (especialmente, Francia e Italia). Un solo visionado de las obras que jalonan la producción de los artistas decimonónicos nos hace plantearnos que, tal vez, esa afirmación es en extremo tajante pues, aunque existe una élite santiaguina que anhela su cercanía a la Europa boyante, las clases populares siguen leyendo en clave colonial y los artistas, independientemente de su origen y experiencia vivencial, encuentran motivos de representación en el arte que se desarrolló en tiempos de la Capitanía General.

El por qué del motivo que llevó a los artistas del siglo XIX a buscar en edificios y decoraciones coloniales los motivos de sus representaciones, encuentra las siguientes respuestas: lo exótico de las representaciones, la riqueza de formas e, incluso, la posibilidad de ensayo y aprendizaje que aportaban las características complejas de este arte, eran motivo suficiente para su representación (Marrero, 2020). Además, el pintoresquismo asociado a ese periodo movería los intereses de artistas que, influidos por ideas románticas y paisajísticas, encontrarían en el país austral un destino perfecto para sus intereses pictorialistas.

La presencia de los artistas mencionados en el país obedece a distintas causas, pero es innegable que más allá de los intereses estrictamente personales que losimpulsaron a radicarse en Chile, todos están motivados 
por el espíritu de aventura, el anhelo de descubrir un mundo nuevo, pujante, no contaminado aún con los signos negativos del progreso civilizador. Su actitud frente a esta realidad, verdaderamente inédita para ellos, los obliga a revisar su propia percepción del mundo, adecuar su visión al nuevo espacio, a una nueva atmósfera de color, a pautas que no obedecen a esquemas institucionalizados de la cultura europea. En síntesis, liberar su visión del pintor, de los prejuicios inherentes a una formación que tenía detrás el peso y la carga de muchos años (Ivelic y Galaz, 2011: 44).

En este contexto, existió un edificio que, en cuanto a su fachada, alimentaba los deseos de originalidad colonial por parte de los artistas del siglo XIX. Nos referimos a la iglesia de la Compañía en Santiago de Chile. Esta contaba con un lienzo pétreo con nichos para esculturas lo cual, unido al almohadillado, a los frontones partidos y a los aletones curvos, ofrecía una imagen digna de ser plasmada. Por si esto no fuera suficiente, el 8 de diciembre de 1863 ardió completamente, dejando una nómina de más de dos mil muertos y un amplio registro del desastre en las más variadas técnicas y soportes.

En este artículo pretendemos abordar las representaciones del incendio acaecido en el santuario jesuita y la trascendencia que estas tienen, como documento fidedigno y primario, para los estudios de arte colonial, creando un ideario general chileno por el cual los individuos cuentan con un referente visual del templo, el cual ha perdurado hasta hoy y que es por todas y todos identificable.

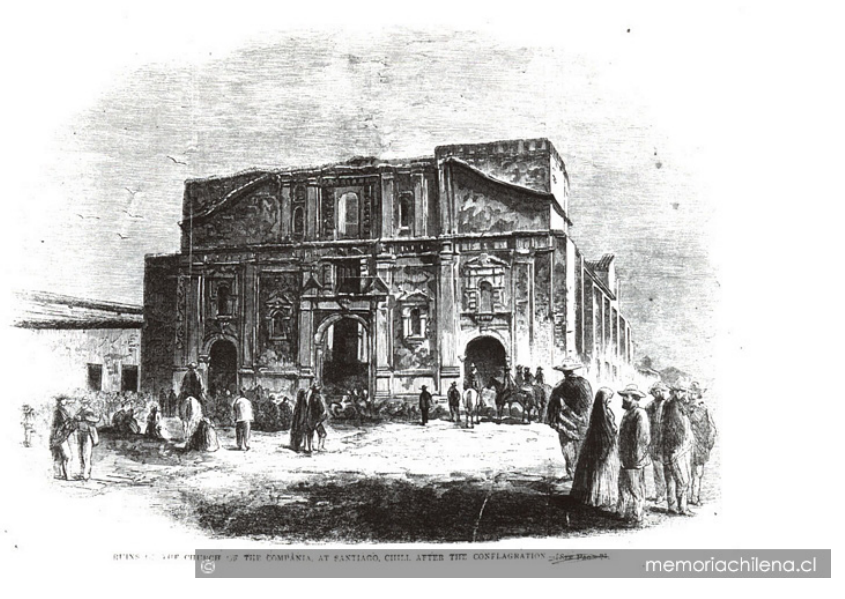

Imagen 1. Ruinas de la Iglesia de la Compañía de Santiago después del incendio, anónimo, 1900, fotografía, id MC: MC0038808. Recuperado de: http://www.memoriachilena.gob.cl/602/w3-article-81381.html

\section{Iglesia de la Compañía, Santiago de Chile. Fundación y destrucción}

La llegada de los jesuitas a Santiago de Chile fue muy tardía, pues arribaron más de cincuenta años después de que Pedro de Valdivia fundara la capital. Junto con P. Baltasar Piñas, se encontraban los frailes Luis de Valdivia, Hernando de Aguilera, Juan de Olivares, Luis de Estrella y Gabriel de Vega y los hermanos Fabián Martínez y Miguel Teleñas (Lozano, 1755: 120). En un inicio manifestaron su intención de no tener residencia fija, ya que "deseaban no ser cargosos a ciudad alguna en particular, resueltos a tenerlas todas por domicilio común, sin asiento fijo, para poder servir a los vecinos de todas las repúblicas, sin la menor incomodidad alguna" (Ovalle, 1888: 358), pero los santiaguinos no lo permitieron, agasajándolos con donaciones. 
Los monjes dominicos les ofrecieron hospedaje hasta que encontraron una residencia permanente. En torno a seis semanas después, se trasladaron a la casa que les había edificado don Rodrigo de Quiroga, Gobernador de Chile y uno de sus más ilustres conquistadores. Esta se ubicaba a una cuadra de la Plaza de Armas, en el mismo lugar en el que posteriormente se hallaría su iglesia principal. Dicha casa fue comprada al maestre de campo don Martin Ruiz de Gamboa por la cantidad de 3600 pesos que reunieron gracias a las donaciones de los vecinos de Santiago. Tras las consabidas reformas para darle a la vivienda la forma y funcionalidad religiosa que correspondía, habilitaron una capilla que, por el costo que supuso (450 pesos donados por el Cabildo), debemos imaginar que era pequeña y pobre, sin demasiados aderezos (Casanova, 1871: 10-11).

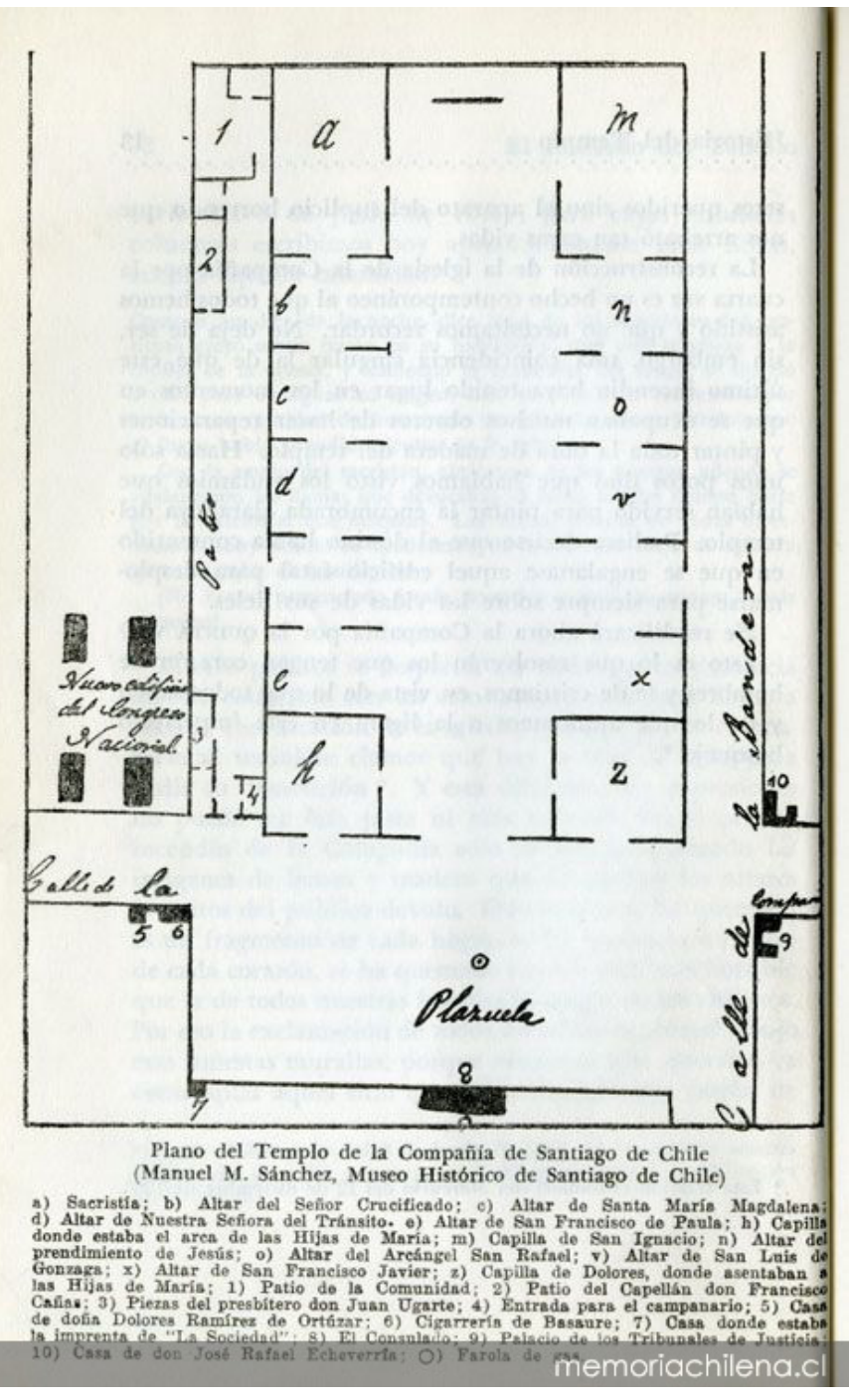

Imagen 2. Plano del Templo de la Compañía de Santiago de Chile, Manuel Sánchez, 1863, lámina, id MC: MC0056653 (Mackenna, 1971: 14). Recuperado de: http://www.memoriachilena. gob.cl/602/w3-article-86345.html

Más allá de la tarea misional, evangelizadora y pastoral (Guarda, 2016: 208-211), nos centraremos en la construcción de la iglesia jesuítica y su trascendencia para el patrimonio santiaguino. Levantada en 1593, sufrió los embates de los terremotos del país austral y un incendio en 1841 
(Mackenna, 1864: 5), aunque siempre mantuvo su traza inicial.

En palabras de Ovalle (1888):

[...] fuera de la catedral es sin controversia la mejor de todas las demás (...), de piedra blanca y la fachada de la puerta principal, muy lucida y airosa, con sus pilastras, molduras y pirámides y en medio, un Jesús de relieve sobre la cornisa principal, todo de admirable arquitectura, como también lo es el crucero de la capilla mayor con su cúpula y lanterna, hechos todos de curiosos y bien labrados florones, lazos y artesones, de dos suertes de madera, blanca y colorada, que hacen muy alegre vista; las pechinas y las capillas de altar mayor y colaterales son también de artesones, pero todas de diferente labor, cuya uniforme variedad hace una muy agradable y proporcionada armonía (272).

La piedra labrada de la fachada, los retablos dorados y los cielos mudéjares son dignos herederos de una tradición constructiva y decorativa que se extendió por las colonias pertenecientes al imperio español, tanto en las Islas Canarias como en Hispanoamérica.

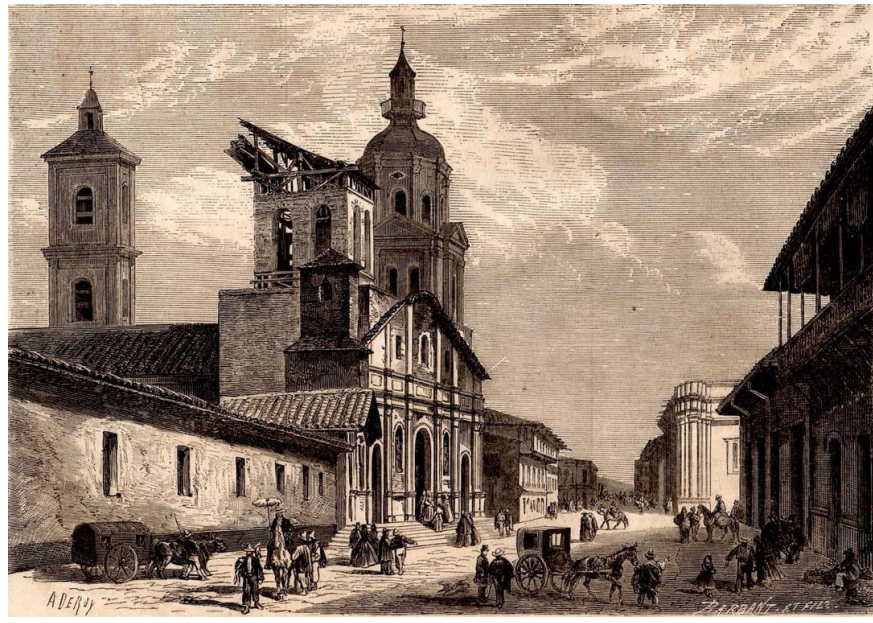

Imagen 3. Iglesia de la Compañía de Jesús, Charles Barbant e hijo (1844-1921), ca. 1880, 15.7 x 22.3 cm, xilografía.[1] Recuperado de: https://philographikon.com/printschile.html

La mencionada iglesia se levantaba incólume en la Calle Compañía, en la actual ubicación del Palacio del ex Congreso Nacional de Chile. En el día del incendio, se celebraba la festividad de la Inmaculada Concepción y el interior del santuario había sido primorosamente adornado, tal como nos describe Casanova (1871), haciendo hincapié en los materiales inflamables utilizados para hacer las velas y la gran cantidad de flores de papel que favorecerían la propagación del fuego. El interior resplandecía con todo el ornato que era capaz de albergar. En el altar mayor, además de los consabidos candelabros de bronce, de mármol y de alabastro, se apreciaban innumerables ramilletes de flores naturales y artificiales, arañas de cristal y de bronce, gasas transparentes de diferentes colores que también adornaban los arcos torales que sostenían la cúpula. Grandes maceteros con flores y árboles combinaban con la representación de ángeles y una amalgama indescriptible de adornos. Entre todo lo reseñable, destacaba la 
sorprendente iluminación que nunca había sido vista en el país. Cubría el altar mayor, los laterales y toda la superficie de la nave central. Cubriendo cornisas y alerones, un cordón de luz se repetía sin descanso. De los materiales constitutivo cabe destacar

[...] que no había en la iluminación gas hidrójeno, sino las siguientes sustancias y en la manera que aquí indicamos; así será fácil comprender bien el oríjen verdadero del incendio. La iglesia se iluminaba con cera, estearina y parafina. La araña del medio del crucero tenía 80 luces de estearina y 16 lámparas de parafina. En cada arco de la nave principal había una araña de ocho velas de estearina y cuatro lámparas de parafina. [...] Las demas luces estaban apagadas, y el número de todas las que debían encenderse más tarde ascendía a 2.200 (Casanova, 1871: 37-39).

La muerte de más de dos mil personas calcinadas por el pavoroso incendio encontró lugar en diarios de todo el mundo como el Frank Leslie's Illustrated Newspaper o en el título del libro publicado en 1863 en el que Mariano Casanova resume el mencionado desastre. Desde América a Australia pasando por el resto de los continentes, el fuego que acabó con la vida de tantos chilenos ha sido considerado uno de los acontecimientos más fatídicos de la historia de la Iglesia Católica. En un texto afectado, con la presencia de algún que otro lamento, Riquelme (1893) se expresa de la siguiente manera:
- ¿I cómo fué?

I fué ¡ai! de tal modo, que la mitad de las casas de Santiago cerraron sus puertas; que en el comercio se agotaron las telas de luto i que durante muchos años se conoció a Chile en Europa principalmente por sus cobres i el incendio de la Compañía, que allí pareció leyenda de ultramar en la inmensidad de su horror, Tanto pareció así que, tiempo después, hallándose en Béljica don Mariano Casanova, hubo de escribir a solicitud de don Manuel Carvallo, nuestro Ministro en Bruselas, i bajo la fé de haberlos presenciado, una relación de esos sucesos para que fueran creídos. Porque, en verdad, ¿cuál otra nación refiere historia semejante de una hecatombe igual, en plena paz de los hombres i de los elementos? ¿I qué fatal maldición pesaba sobre aquel templo, destruido ya cuatro veces antes de su ruina postrera? (9).

El incendio y la ingente cantidad de muertes, en su mayoría mujeres, dio paso a dos vertientes: una anticlerical que apostaba, aun más si cabe tras los comienzos de una secularización incipiente que ya había encontrado adeptos en Chile, por la laicidad del estado y la otra que, defensora del catolicismo, arrimaba las culpas a la superstición y la superchería, propias de una población que había abandonado las buenas prácticas por la idolatría (Serrano, 2008). Reflexionando sobre la primera, es interesante la siguiente cita:

El incendio de la Compañía proyectó su trascendencia en el desarrollo del sentimiento religioso chileno y de la política anticlerical que caracterizó a las administraciones de 
Pinto y Santa María y la segunda mitad de la de Errázuriz. Los librepensadores estigmatizaron el sensualismo pagano del culto dirigido por Ugarte. (...) El paganismo de tal culto a María atrajo a la mujer; pero, al herir el austero ascetismo castellano, alejó a los hombres. Sin proponérselo, los marianistas produjeron el distanciamiento moral en los hogares. Los maridos y los padres se volvieron contra una fuerza que minaba su autoridad y los separaba del afecto filial y conyugal. En la lucha religiosa que se avecina, el clero contará en su favor con el 98\% de las mujeres, pero va a tener en su contra a más del 80\% de los hombres. El propósito de desvincular de la Iglesia el estado civil y los cementerios avanzó en poco tiempo una jornada mucho mayor que discurrida desde la Independencia hasta 1863. Antes de tres años, el diputado don Ricardo Claro y Cruz presentaba un proyecto de ley de matrimonio civil. (Encina y Castedo, 1961: 1246)

Por su parte, los defensores de la religión achacaron el incidente a la mala praxis de aquellos que se habían adueñado de los tempos, abogando por la vuelta del poder sobre las iglesias a la figura de los sacerdotes:

En efecto, los perseguidores modernos de nuestra santa relijion, al ensañarse contra ella para encubrir su intolerancia, han afectado cierto respeto al culto que se tributa en el recinto sagrado, proclamado como principio que la relijion dentro de sus tempos o reoconoce otro poder que el de sus ministros. Los fieles en todas partes no tienen tasadas las horas en que pueden acudir al templo, $\mathrm{i}$ la autoridad profana no envia sus ajentes a contar el número de los que pueden ser admitidos al ejercicio de su culto, determinar el orden de su colocacion, contar las luces i hasta designar las puertas i ventanas del edificio, ni mas ni menos que si se tratara de las cárceles i otros establecimientos que inmediatamente dependen de los majistrados civiles. No pretendemos por esto que en los templos no haya órden ni concierto i que dejen de tomarse las precauciones prudentes para evitar desgracias, solo decimos que toca establecerlo a la autoridad de la Iglesia, única que es competente para determinar hasta que grado son compatibles con las conveniencias del espíritu los cuidados del cuerpo. (Valdivieso, 1864: 9)

A pesar de aunar esfuerzos, la presencia de las Compañías de Aguadores y la Brigada Cívica del Batallón de Zapadores Bomberos no supuso cambio en el trágico destino que corrieron los fieles congregados en el interior del templo. Conscientes de la necesidad de crear un grupo más organizado y eficaz para la extinción de futuros incendios, nace el Cuerpo de Bomberos de Santiago (León, 2017: 445-450; Valdés, 1900).

En 14 de diciembre de 1863, seis días después del desastre, se firma un Decreto Supremo que ordena la demolición de las ruinas de la Compañía, concediendo diez días para la extracción de los cadáveres que están sepultados al interior de dicho templo. Años después, la iglesia reclamará los terrenos sobre los que se levantara la iglesia jesuítica, expresándose del siguiente modo: 
Debiendo éste no ser aplicado a ningun uso profano, segun acredita la nota del señor Ministro de aquella época, dirijida al Ilmo. Metropolitano con fecha 12 del citado mes i año, en la cual se previene pidiéndole por parte del gobierno se le autorice para decretar la demolicion "que no se hará tal uso de aquel suelo." No he dudado al dirijirme a V.S., quien como conocedor de las leyes canónicas i civiles vijentes entre nosotros, tenga a bien por exijirlo así los principios de la mas estricta justicia, hacer que aquel terreno sea restituido al poder de la Iglesia, mandándolo poner a disposicion del encargado de velar por los intereses de aquélla. (Cañas, 1867: 3)

Con la inauguración del monumento a las víctimas de tan sonado desastre, se cierra la vida de un santuario que llegó a ser cabeza insigne de la arquitectura colonial en la Capitanía General de Chile.

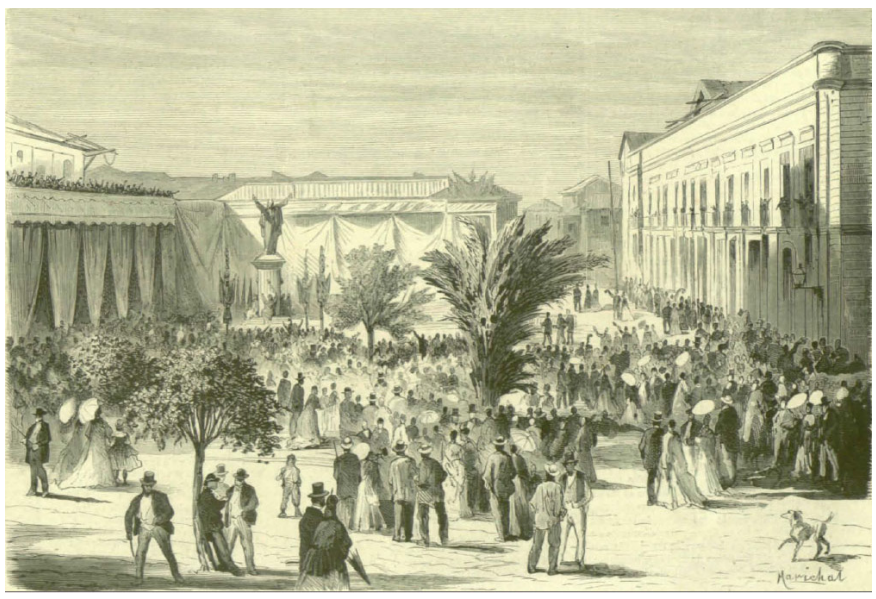

Imagen 4. Inauguración del monumento a las víctimas, Gastón Marichal (1850-1950), 30 de abril de 1874, grabado, La Ilustración Española y Americana, Madrid, p. 253. Recuperado de: http://www.cervantesvirtual.com/servlet/ SirveObras/46805010214468729532279/204959_013. pdf

\section{Representaciones decimonónicas del templo jesuita y su incendio}

Las representaciones del incendio que destruyó la iglesia de la Compañía el 8 de diciembre de 1863 pueden agruparse, según el momento plasmado, en cuatro grandes escenas: el desarrollo del incendio desde el exterior, el fuego consumiendo el interior y la agonía de los fieles, el lamento ante la iglesia y transporte de los cadáveres, y el edificio jesuita después del incendio. A continuación, vamos a ofrecer diferentes obras que ejemplifican los grupos anteriormente propuestos.

El primero atiende al incendio visto desde el exterior, encontrando imágenes que referencian el momento anterior a la caída las torres; el instante posterior al derrumbe de los mencionados elementos, así como el de la cúpula; el detalle de las personas, todavía algunas en llamas, reunidas a los pies de la fachada principal:

[...] subieron las llamas, inquietas y enormes, abrazando la cúpula entera, construída de pura madera; aumentándose y alzándose con nuevo pábulo, parecían llegar a una gran altura en el cielo que se mantenía en toda tranquilidad. Avanzando el fuego por dentro, desde el coro hasta la fachada, el humo iba traspasando sucesivamente los tejados del templo, precediendo a las llamaradas que no tardaron en asomar en pos de 
él. La única torre del frente vió así llegar su turno; primeramente la envolvió el humo que se hacía denso poco a poco, que luego arrastraba fuegos de materias que volaban con él, y que se tornó en nueva llama que lamía la torre entera hasta más arriba de su empinada flecha. [...] Linterna y flecha, devoradas ya en su base, se inclinaron entonces ligeramente, crujieron, y en seguida, como un tizón ardiente arrojado desde el cielo, cayeron juntas envueltas en humo y fuego y marcando el trayecto con chispas y destellos como de pirotécnica (Subercaseaux, 1936: 75-80).

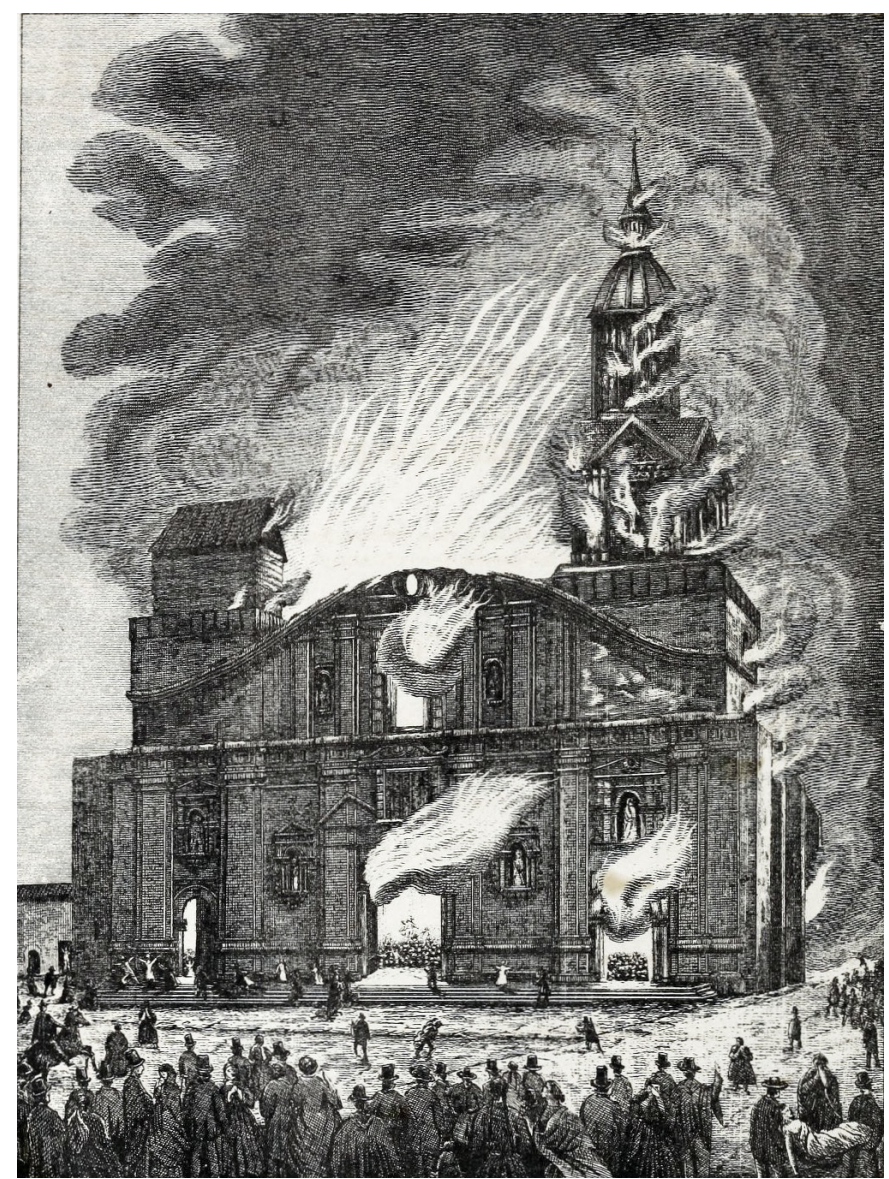

Imagen 5. Relación del incendio de la Compañía acaecido el 8 de diciembre de 1863, anónimo, 1864, litografía, id MC: MC0052656 (Mackenna, 1864). Disponible en: http://www.memoriachilena.gob. cl/602/w3-article-85551.html

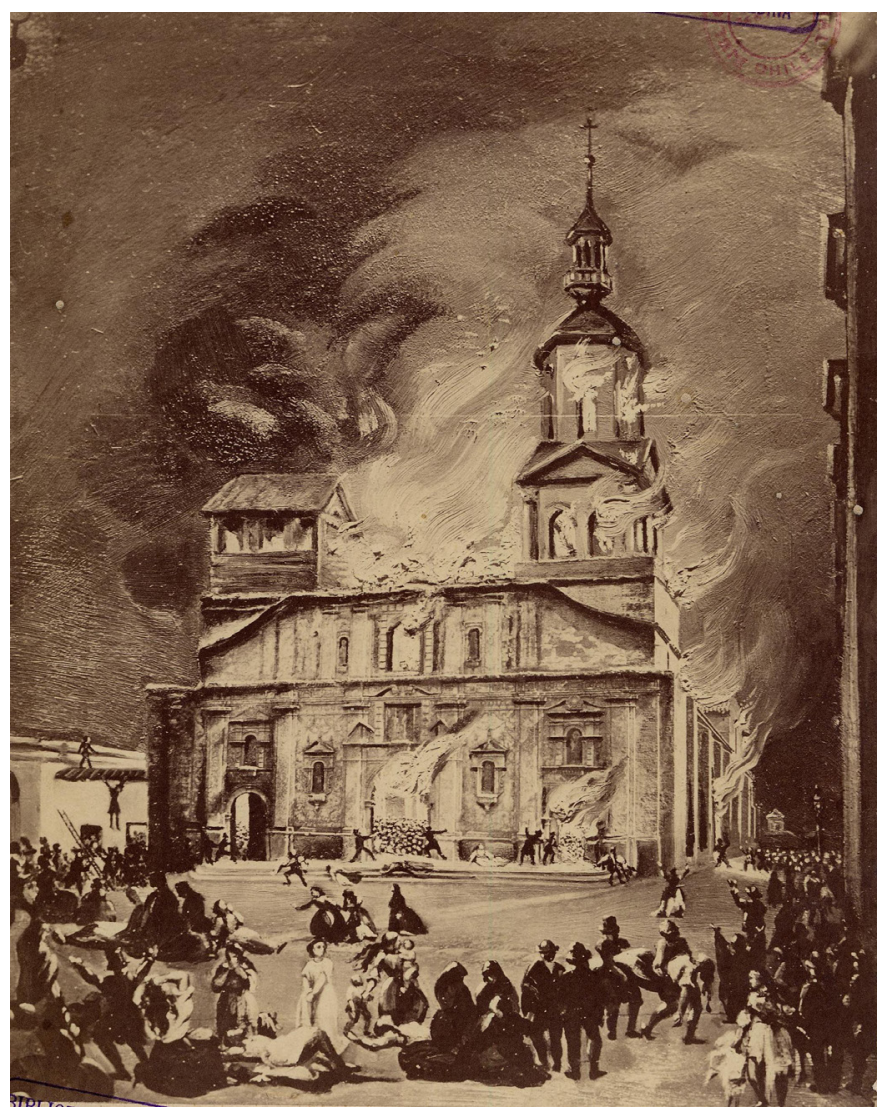

Imagen 6. Incendio de la iglesia de la Compañía, anónimo, 1863, 31 x $23 \mathrm{~cm}$, fotografía, id BND: 316100. Recuperado de: http://www.bibliotecanacionaldigital.gob.cl/bnd/632/w3-article-316100. html 


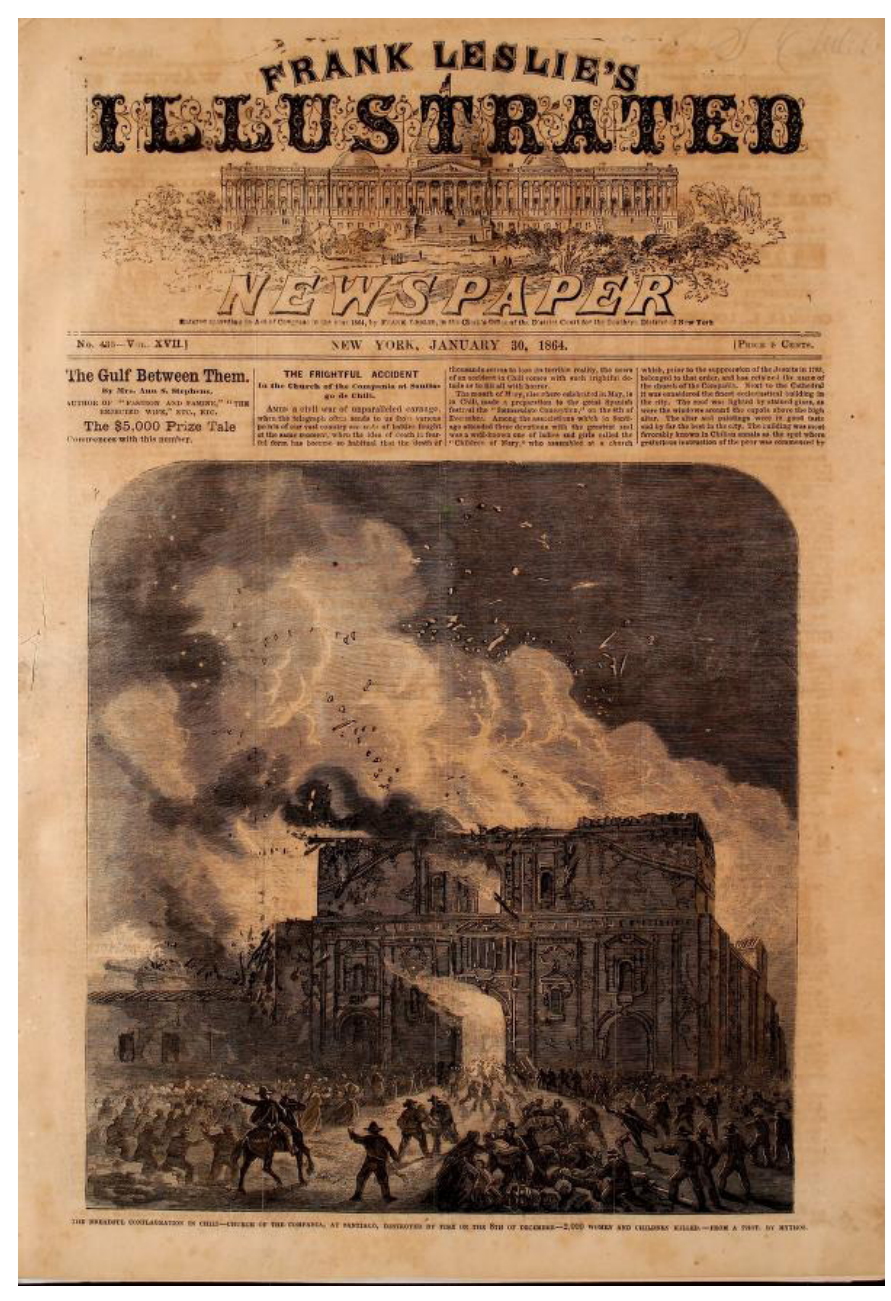

Imagen 7. Incendio de la iglesia de la Compañía, 30 de enero de 1864, litografía de una fotografía de Mythos, Frank Leslie's Illustrated Newspaper, New York, p. 289. Recuperado de: https://archive. org/details/franklesliesilluv1718lesl/page/288/ mode/2up?view=theater

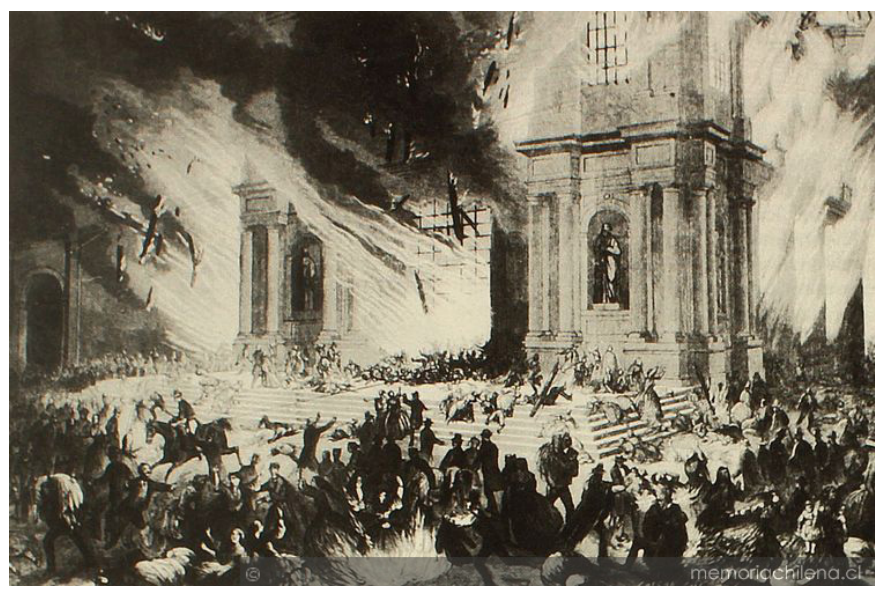

Imagen 8. Incendio de la iglesia de la Compañía, Ernest Charton de Treville (1816-1877), 1863, lámina, id MC: MC0056643 (Fredes, 2004: 46). Recuperado de: http://www.memoriachilena. gob.cl/602/w3-article-86337.html

Igualmente, es interesante la lámina de Ernest Charton de Treville en la que se observa una mujer envuelta en llamas que nos recuerda de manera poderosa a lo expresado en el Diario El Ferrocarril en 10 de diciembre de 1863, cuando dice “(...) En los umbrales mismos han perecido centenares de personas, quemadas a la vista de un pueblo inmenso a que dirijian sus brazos en ademan suplicante i que en esos momentos era impotente para salvarlas".

Otra tipología iconográfica es la del interior del templo en el momento en el que se convierte en horno sin posibilidad de escapatoria. El fuego se muestra con un poder incontrolable, mientras los fieles intentan salir por la única puerta operativa y que, por la acumulación de cuerpos, pronto dejará de ser transitable. Los detalles decorativos se agitan, las lámparas de mueven con furia de un lado al otro y, en el caso de la pintura de Hughes, 
los tonos rojizos predominan en una escena en la que se entremezcla la desesperación y la muerte.

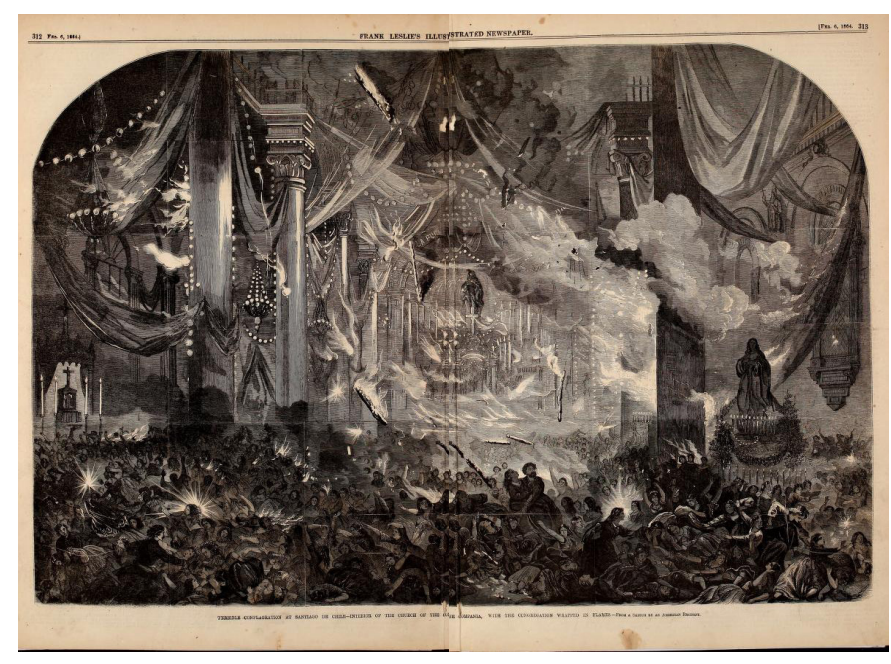

Imagen 9. Interior de la iglesia de la Compañía durante el incendio, anónimo americano residente en Chile, 6 de febrero de 1864, papel, Frank Leslie's Illustrated Newspaper, Washington, pp. 312-313. Disponible en: https://archive. org/details/franklesliesilluv1718lesl/page/312/ mode/2up?view=theater

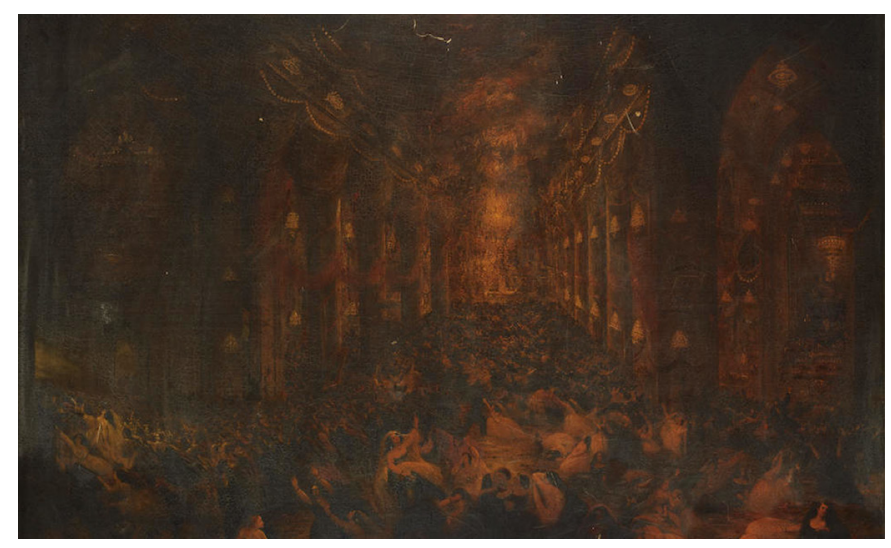

Imagen 10. The Destruction by Fire of the Church de la Campania, Nathan Hughes (1849-1870), 18631870, óleo sobre lienzo, 137 x $193 \mathrm{~cm}$. Disponible en: https://www.bonhams.com/auctions/21827/ lot/246/

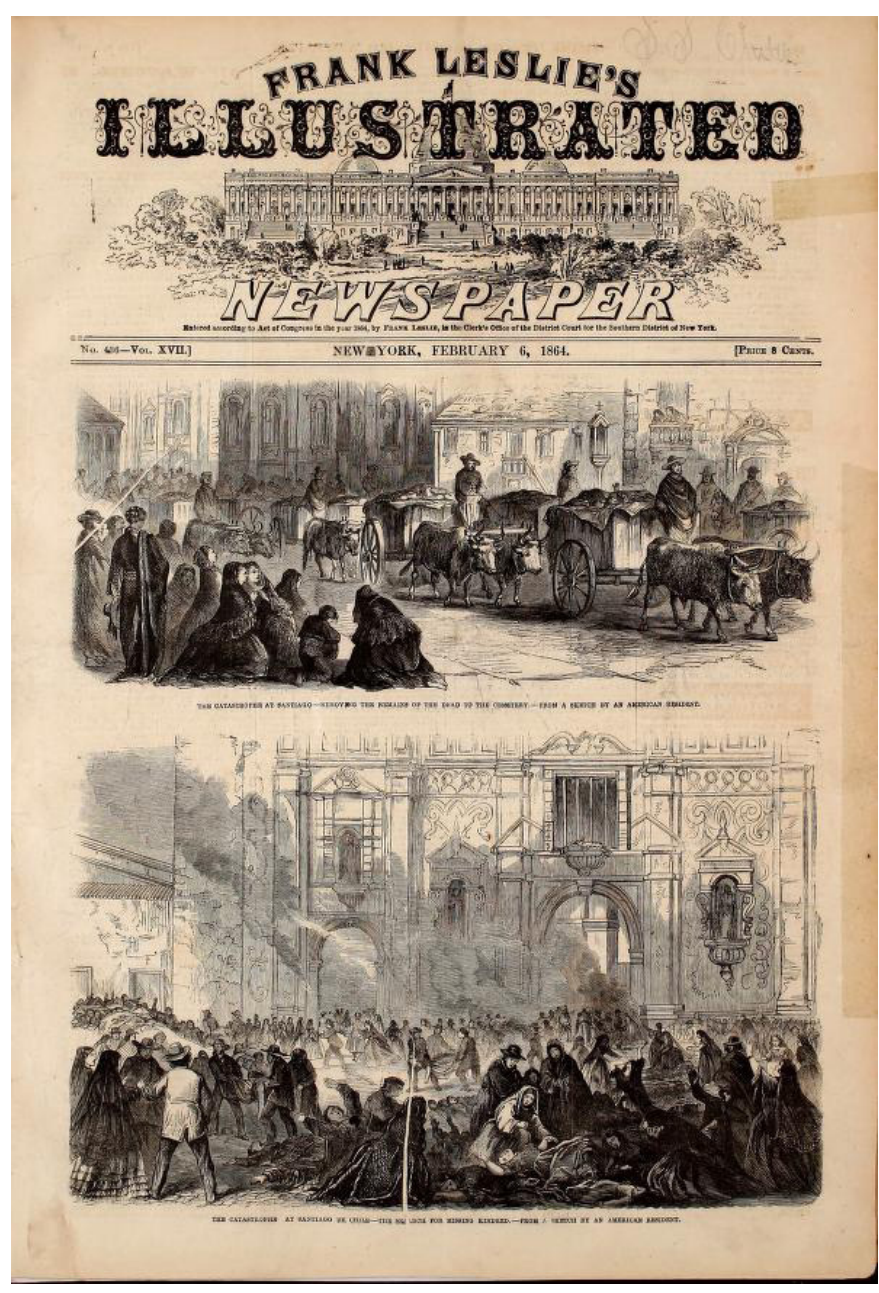

Imagen 11. Llevando los cadáveres al cementerio[2] / Búsqueda de familiares perdidos, anónimo americano residente en Chile, 6 de febrero de 1864, papel, Frank Leslie's Illustrated Newspaper, New York, p. 305. Disponible en: https://archive. org/details/franklesliesilluv1718lesl/page/304/ mode/2up?view=theater

En una hora, el incendio dejó más de dos mil cadáveres y una iglesia destruida por completo. Los 
cuerpos carbonizados eran imposibles de identificar, por lo que fueron trasladados en carretas a una fosa común frente al Cementerio General. Tal como explica Abdón (1936): "Las autoridades se ocupaban en hacer conducir los cadáveres al cementerio. Allí pereció una buena parte de la sociedad más aristocrática de Santiago, como luego comenzó a saberse. Casi no quedó familia distinguida que no contase alguna víctima" (8289). Las representaciones realizadas al respecto muestran una especie de Piedad colectiva donde las figuras enlutadas se lamentan ante el paso de los cadáveres que son llevados al camposanto.

Finalmente, contamos con un dibujo Paul Treutler que da testimonio del día posterior al desastre, cuando todavía la ciudad se afanaba por retirar los cadáveres carbonizados de los fieles muertos en el incendio. En palabras de Martina Barros (1942):

Dos días después se pudieron extraer los cadáveres hacinados entre las ruinas del templo y el Intendente comenzó a trasladarlos al Cementerio General. No había carros fúnebres en que hacerlo de modo que hubo que recurrir a los simples carretones que cubrían como se podía, hasta con pasto y hasta el pasto se acabó; el olor a carne quemada se expandió por todos los alrededores de la iglesia hasta hacerse insoportable. (83)

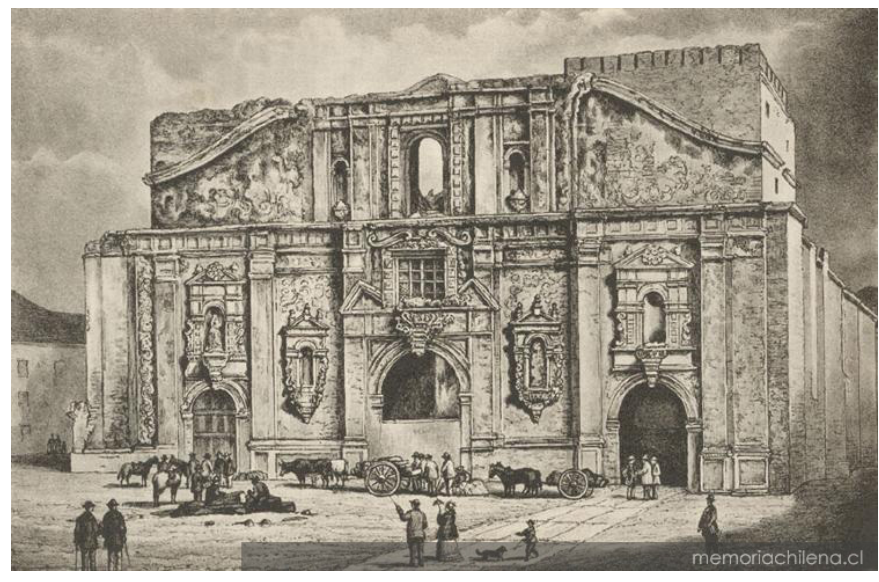

Imagen 12. Iglesia de la Compañía de Jesús, Paul Treutler(1822-1887), 1863, lámina, id MC: 0007436. Recuperado de: http://www.memoriachilena. gob.cl/602/w3-article-68045.html

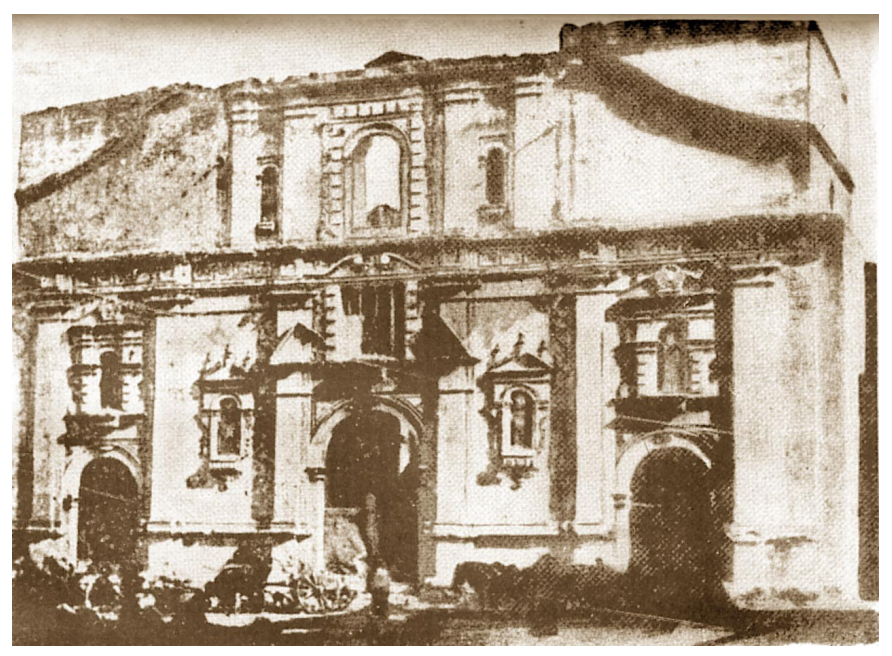

Imagen 13. Carretas retirando los cuerpos calcinados, anónimo, 1863, fotografía (Peña 1944). Recuperado de: http://urbatorium.blogspot. com/2009/04/el-monumento-las-victimas-del-incendio.html 


\section{Conclusiones}

En este primer acercamiento a la importancia de las tipologías iconográficas para la gestación de una identidad nacional, Chile se nos descubre como un lugar ideal para nuestras investigaciones. En medio del azote de agentes destructores del patrimonio, ya sea por causa natural o antrópica, la pérdida de bienes y obras de arte, en su mayoría religiosos, favorece el debate de la secularización social y la laicidad del Estado. Esto no debiera extrañarnos, máxime si tenemos en cuenta que el país austral mira hacia la Europa decimonónica buscando referentes para la recién estrenada República, encontrando ejemplos como la Revolución Francesa de 1789, la Revolución Industrial de 1820 o la Desamortización de Mendizábal en España en 1836. La llegada de las ideas ilustradas abre el debate de limitar la capacidad de injerencia de la religión en la vida social y política de los chilenos, y el incendio de la iglesia de la Compañía, a modo de paralelismo fatídico, aviva las llamas de la discusión entre ambos bandos, laicos y religiosos.

El estudio de la representación artística del mencionado desastre se postula como tipología iconográfica que cuenta con distintos momentos a plasmar: el incendio desde el exterior, el fuego consumiendo el interior, el lamento ante la iglesia y transporte de los cadáveres, y el edificio después del incendio. Esto plantea la posible búsqueda de nuevas tipologías que respondan a la formación de una identidad nacional chilena a partir de las virtudes visuales de las obras de arte.
Finalmente, los estudios de piezas artísticas que toman como fuente de representación obras desaparecidas, permiten desarrollar estudios posteriores que pongan en valor dichos elementos patrimoniales. En el caso que nos ocupa, la iglesia de la Compañía ha destacado como uno de los conjuntos arquitectónicos más notables y paradigmáticos de la Capitanía General de Chile, concluyendo que la desaparición de las obras de arte no es obstáculo para su estudio

\section{Bibliografía}

Barros de Orrego, M. (1942): Recuerdos de mi vida, Santiago de Chile, Orbe.

Cañas, F. (1867): Reclamo dirijido al supremo gobierno con fecha 7 dejunio de 1865 , sobre el terreno perteneciente a los bienes que quedaron de la iglesia de la Compañía, Santiago de Chile, Impr. del Independiente.

Casanova, M. (1863): Resúmen histórico del gran incendio de la Compañía: acaecido en la noche del día 8 de diciembre de 1863 y en el cual perecieron asfixiadas o devoradas por las llamas más de dos mil personas: una parte de las cuales pertenecian a las principales familias de la capital, Valparaíso, Librería Española de Nicasio Ezquerra.

Casanova, M. (1871): Historia del templo de la Compañía de Santiago de Chile y de su incendio acaecido el 8 de diciembre de 1863, Valparaíso, Impr. del Mercurio.

Cifuentes, A, (1936): Memorias, vol. 1, Santiago, Editorial Nascimento. 
Encina, F. y Castedo, L. (1961): Resumen de la Historia de Chile, Santiago de Chile, Zig-Zag.

Fredes Aliaga, C. (2004): 150 años de honor y gloria: notas para una historia de los Cuerpos de Bomberos de Chile, Chile, Junta Nacional de Cuerpos de Bomberos.

Guarda, G. (2016): La Edad Media de Chile. Historia de la iglesia. Desde la fundación de Santiago a a incorporación de Chiloé(1541-1826), Santiago de Chile, Pontificia Universidad Católica de Chile.

Ivelic, M. y Galaz, G. (2011): La Pintura en Chile. Desde la colonia hasta 1981, Valparaíso, Ediciones Universitarias de Valparaíso.

León Echaiz, René (2017): Historia de Santiago, Santiago de Chile, Nueve Noventa ediciones.

Lozano, P. (1755): Historia de la Compañía de Jesús de la Provincia del Paraguay, Madrid, Impr. de la viuda de Manuel Fernández.

Marrero Alberto, A. (2020): "El dibujo y la construcción del arte colonial chileno. Desde Alonso de Ovalle hasta el siglo XIX”, Cuadernos de Historia del Arte, 39, pp. 239-267

Ovalle, A. (1888): Histórica Relación del Reino de Chile y de las Misiones y Ministerios que ejercita en él la Compañía de Jesús, Santiago, Impr. Ercilla.

Panofsky, E. (2004): El significado en las artes visuales, Madrid, Alianza Editorial.

Peña Otaegui, C. (1944): Santiago de siglo en siglo: comentario histórico e iconográfico de su formación y evolución en los cuatro siglos de su existencia, Santiago de Chile, Zig-Zag.

Serrano, S. (2008): ¿Qué hacer con Dios en la República? Política y secularización en Chile (1845-1885), Santiago de Chile, Fondo de Cultura Económica.

Subercaseux Vicuña, R. (1936): Memorias de ochenta años: recuerdos personales, críticas, reminiscencias históricas, viajes, anécdotas, Santiago de Chile, Editorial Nascimento.

Treutler, P. (1882): Fünfzehn Jahre in Süd- Amerika an den Ufern des Stillen Oceans, Leipzig, Welt post.

Valdés Vergara, I. (1900): El Cuerpo de Bomberos de Santiago: 1863-1900: noticias para su historia y datos sobre otros Cuerpos de Bomberos de Chile, Valparaíso, Impr. Sud-Americana.

Valdivieso, R. (1864): Pastoral del Ilustrisimo y Reberendisimo Señor Arzobispo de Santiago sobre el incendio de la Compañia i su reparación, Santiago de Chile, Impr. del Correo.

Vicuña Mackenna, B. (1864): Relación delincendio de la Compañía acaecido el 8 de diciembre de 1863, Santiago de Chile, Impr. del Ferrocarril.

Vicuña Mackenna, B. (1971): El incendio del Templo de la Compañia de Jesús: fundación del Cuerpo de Bomberos de Santiago, Santiago de Chile, Edit. Francisco de Aguirre. 


\section{Notas}

[1] Versión en grabado: Vue de l'eglise de la Compagnie, place du Consulat, a Sant-Yago de Chili, detruite par un incendie qui a coute la vie a deux mille personnes, Clara Filleul, 1857.

[2] Encontramos una representación casi idéntica, aunque no queda claro cuál de las dos es la original y cuál es la copia. Para la consulta de la mencionada imagen: Incendie de l'église de 'La Compaignie', à Santiago (Chili): Transport des restes des victimes, Ernest Charton de Treville, 1863-1877, grabado, Bibliothéque Nationale de France. Recuperado de: http://www.archivovisual.cl/search/author 